\title{
Hyponatraemia during Low-Dose Carbamazepine Therapy
}

\author{
F. Salawu ${ }^{1}$ and A. Danburam ${ }^{2}$ \\ ${ }^{1}$ Department of Medicine, State Specialist Hospital, Maiduguri 600001. Nigeria \\ ${ }^{2}$ Department of Medicine, Federal Medical Centre, Yola 640001. Nigeria \\ Reprint requests to: Dr. F. K. Salawu, P. O. Box 246, Maiduguri 600001, Nigeria. \\ E-mail: $\underline{\text { drabdulsalawu@yahoo.com }}$
}

\begin{abstract}
We report the syndrome of inappropriate antidiuresis as a much earlier side-effect of carbamazepine administration in a 29-year Nigerian female patient with generalized tonic-clonic seizures. Although asymptomatic, the biochemical abnormality improved after discontinuation of carbamazepine. Hyponatraemia developed after rechallenge with controlled release carbamazepine. The authors suggest that serum sodium levels be carried out before commencement of carbamazepine and caution be used in prescribing carbamazepine to patients with low or borderline low sodium values.
\end{abstract}

Key words: Carbamazepine, hyponatraemia

\begin{abstract}
Résumé
Nous rapportons le syndrome de l'antidicirose inappropriée comme beaucoup plus tôt aux effets secondaires de l'administration carbamazepine chez une malade nigériane âgée de 29 ans avec de la convulsion toniques clonique généralisée. Bien que asymptomatique, l'anomalie biochimique avait amélioré après l'arrêt de la carbamazepine. L'hyponatemie avait développé après ré administration de la carbamazepine contrôlée. Les auteurs suggèrent que les niveaux de sérum de sodium devront être effectués avant le début de la carbamazephine et de prudence être utilisée dans l'ordonnance de la carbamazepine pour des patients atteints de la faible ou basse limite des valeurs de sodium.
\end{abstract}

Mots clés: Carbamazepine, hypenatrémie

\section{Introduction}

Carbamazepine is widely used in Nigeria in the treatment of seizure disorders and of trigeminal and other neuralgias. It has found a role in the prophylaxis of affective disorders. ${ }^{1}$ It is used in adults and children in the prophylaxis management of partial seizures, generalized tonic-clonic seizures and mixed seizure patterns. It has been used in the symptomatic management of the acute phase of schizophrenia as an adjunct to therapy with an antipsychotic agent in patients who fail to respond to an adequate trial of the antipsychotic alone. ${ }^{2}$ Although hyponatraemia is a well-recognized side-effect of carbamazepine therapy, it has previously been reported only at moderate or high doses and usually after weeks or months of treatment. $^{3-9}$ This paper reports a case of carbamazepine-induced hyponatraemia in a young Nigerian woman being treated for generalized tonicclonic seizures.

\section{Case report}

A 29-year-old Nigerian female presents with a 3-month history of generalized tonic-clonic seizures. Her first seizure occurred when she was 17 years, and her second seizure occurred 2 years after that. She chose not to start antiepileptic drugs at that time because the seizures were rare, but she has now had five seizures over the past 6 months. After seven days of treatment with carbamazepine $200 \mathrm{mg}$ twice daily increasing to $400 \mathrm{mg}$ twice daily, a routine estimation of plasma electrolytes gave sodium of $121 \mathrm{mmol} / \mathrm{l}$ with chloride of $89 \mathrm{mmol} / \mathrm{l}$; other results were within normal limits. She had a normal plasma sodium level of $135 \mathrm{mmol} / \mathrm{l}$ before commencement of carbamazepine therapy. She did not use other medications such as diuretics and antipsychotics that could cause hyponatraemia. Carbamazepine was discontinued, leading to a rise in plasma sodium to reach a normal value after two weeks without any medication. Physical examination and investigations, including chest and skull radiographs, showed no alternative explanation for the hyponatraemia such as meningitis, encephalitis or pulmonary tuberculosis.

The suspected role of carbamazepine in producing this effect was confirmed by a period of 
rechallenge with the drug, during which plasma electrolyte levels were monitored daily. Although plasma carbamazepine levels could not be monitored, the dose given was $200 \mathrm{mg}$ on the first day and $200 \mathrm{mg}$ twice daily thereafter. On day 3 , after a total dose of $600 \mathrm{mg}$, the sodium level was $132 \mathrm{mmol} / \mathrm{L}$, just below the laboratory's normal range $135-145 \mathrm{mmol} / \mathrm{L}$. The following day it was $128 \mathrm{mmol} / \mathrm{L}$ with a plasma osmolality of $255 \mathrm{mmol} / \mathrm{L}$ and urine osmolality of 325 $\mathrm{mmol} / \mathrm{L}$. On stopping carbamazepine, the electrolyte returned to normal in four days. At no time during the period of hyponatraemia did the patient show symptoms. Her medication was changed to phenytoin capsule $300 \mathrm{mg}$ nocte.

\section{Discussion}

The goal of treatment with antiepileptic drugs (AEDs) is complete control of seizures without side effects. The choice of initial therapy is perhaps the most critical juncture in the care of epilepsy patients, as many patients will remain on this therapy for years, if not a lifetime. There is no such thing as an 'ideal' AED that would be the first choice in patients with epilepsy or even all patients with a given epilepsy syndrome. This case demonstrates the potentially profound disturbance of water balance, which can occur as result of carbamazepine monotherapy. We attributed the acute hyponatraemia to carbamazepine since there was no concomitant use of medications associated with hyponatraemia. Carbamazepine has led to hyponatraemia in patients with epilepsy, neuralgia, mental retardation, and psychiatric disorders with a frequency varying from 4.8 to $40 \%{ }^{10}$ It shows that this side-effect can occur at lower doses and after much shorter periods than has previously been recognized.

Possible mechanisms for the antidiuretic effects of carbamazepine have been proposed. Altered sensitivity to serum osmolality by the hypothalamic osmoreceptors appear likely, but an increased sensitivity of the renal tubules to circulating antidiuretic hormone cannot be explained. It suggests the need to estimate plasma electrolytes in patients complaining of side-effect such as nausea, headache and dizziness-all symptoms of hyponatraemia-in the first few days of carbamazepine therapy. Several risk factors have been reported to increase the risk of hyponatraemia including age greater than 40 years, concomitant use of medications associated with hyponatraemia, menstruation, psychiatric conditions, surgery, psychogenic polydipsia and female gender. ${ }^{11}$ Most patients with carbamazepine-induced hyponatraemia are asymptomatic. In rare cases, water intoxication has been reported, ${ }^{10}$ necessitating treatment discontinuation. We therefore suggest that caution be used in prescribing carbamazepine to patients with low or borderline sodium values.

\section{References}

1. Ballenger JC, Post RM. Carbamazepine in manicdepressive illness. A new treatment. Am J Psychol. 1980;37:782-790.

2. American Psychiatric Association. Practice guideline for the treatment of patients with schizophrenia, second edition. Am J Psych 2004; 161:1-56.

3. Rado JP. Water intoxication during carbamazepine treatment. BMJ. 1973;3:479.

4. Henry DA, Lawson DH, Reavey P, Renfrew J. Hyponatraemia during carbamazepine treatment. BMJ. 1977;8:83-84.

5. Stephens WP, Espir ME, Tattersall RB, et al. Water intoxication due to carbamazepine. BMJ. 1977;19:754-755.

6. Ashton MG, Ball SG, Thomas TH, Lee MR. Water intoxication associated with carbamazepine treatment. BMJ. 1977;1:11341135.

7. Sordillo P, Sagransky DM, Mercado R, Michelis FM. Carbamazepine-induced syndrome of inappropriate antidiuretic hormone secretion. Arch Intern Med. 1978;138:299-301.

8. Perucca E, Garratt A, Hebdige J, Richens A. Water intoxication in epileptic patients receiving carbamazepine. J Neurol Neurosurg Psychiatry. 1978;41:713-718.

9. Byrne E, Wong CH, Chambers DG, Rice JP. Carbamazepine therapy complicated by nodal bradycardia and water intoxication. Aust NZ Med J. 1979;9:295-296.

10. Van Amelsvoort T, Bakshi R, Devaux CB, Schwabe S. hyponatraemia associated with carbamazepine and oxcarbazepine therapy: a review. Epilepsia. 1994;35:181-188.

11. Kuz GM. Carbamazepine-induced hyponatraemia: assessment of the risk factors. Ann Pharmacother. 2005;39:1943-1946. 